\title{
QUALIDADE PÓS-COLHEITA DE BANANA PRATA ANÃ ARMAZENADA SOB DIFERENTES CONDIÇÕES ${ }^{1}$
}

\author{
LETÍCIA VIVIANI² \& PAULO MARTINS LEAL ${ }^{3}$
}

RESUMO - O manuseio inadequado na pós-colheita tem sido responsável pela desvalorização da banana no mercado interno e pela perda de oportunidade de exportação. Outro aspecto observado é que o comércio de banana é fortemente afetado pela má apresentação dos frutos e embalagens. Este trabalho teve como objetivo avaliar a qualidade pós-colheita de frutos da bananeira Prata-Anã, por análises físico-químicas e sensoriais, comparando o armazenamento refrigerado $\left(13^{\circ} \mathrm{C}\right)$ e o realizado em temperatura ambiente, empregandose diferentes tipos de embalagens (caixa de madeira tipo torito, com capacidade para $18 \mathrm{~kg}$, com revestimento de papelão para os frutos, caixa de madeira tipo $1 / 2$ caixa, com capacidade para $13 \mathrm{~kg}$, com revestimento de papelão para os frutos e caixa de papelão com capacidade para $18 \mathrm{~kg}$ ). Também, foram avaliados os danos físicos que ocorrem na banana durante transporte até o centro de distribuição e após a climatização. A conservação em ambiente refrigerado aumentou sua vida útil. Não houve diferença significativa entre as embalagens quanto à conservação das frutas, tanto nos atributos indicativos de maturação, quanto no aumento dos danos físicos. Sendo assim, essas embalagens podem ser utilizadas como alternativa de proteção ao fruto.

Termos para indexação: Musa spp., processamento, acondicionamento.

\section{QUALITY EVALUATION OF POST HARVEST BANANA 'PRATAANÃ' ASSOCIATED TO PACKING}

ABSTRACT - The inadequate handling during the post-harvest has been responsible by the lost of value of the product in the internal market, and lost of opportunity of exportation of this Brazilian fruit. The other observed aspect is that the commerce of banana is highly affected by the bad visual aspects of the fruits and inadequate packing. Inside of this context, this research has, as major objective, the evaluation of post-harvest quality of banana fruits, variety Prata Anã. Experiments were realized to evaluate the quality variation, appearance, and colorin until the fruits were inappropriate for consumption, using physical-chemical and sensorial analysis, by comparing cold storage at $13^{\circ} \mathrm{C}$ and maintenance of the products at natural environment with no temperature control. The fruits of banana during the experiments were packed in three different packing (wood box type "torito" with capacity for 18kg and cardboard wrapper, wood box type " $1 / 2$ caixa", with capacity for $13 \mathrm{~kg}$ and cardboard box with capacity for $18 \mathrm{~kg}$ ). Physical or mechanical damages were, also, evaluated during the transport of the fruits from the packing house to the distribution center, and after acclimatization. Keeping the fruits at refrigerated environment increased the life storage in five days. The packing used did not promote difference in the conservation of the fruits, neither in the indicatives attributes of maturation and also in the increase of physical damages.

Index terms: Musa spp., processing, package

\section{INTRODUÇÃO}

O Brasil destaca-se no mercado internacional como sendo um dos maiores produtores de frutas. Devido a sua grande diversidade climática, o País produz desde frutas adaptadas ao clima temperado até as tipicamente tropicais. A produção de banana no Brasil, em volume, é superada apenas pela laranja; todavia, apresenta grande importância na alimentação, por ser o maior consumidor mundial, mesmo sendo o terceiro em produção (Icepa, 2002). Seu cultivo é realizado em todos os Estados da Federação, desde a faixa litorânea até os planaltos do interior (Alves, 1999). Dentre os municípios do norte de Minas, Janaúba destaca-se como a capital do pólo fruticultor. Atualmente, existe uma área de aproximadamente 12 mil hectares plantados com frutas nesta região, sendo que $67 \%$ da área irrigada corresponde ao plantio de banana (predominantemente bananas do grupo Prata). Olorunda (2000) expõe que as perdas em bananas podem ter origens mecânicas, fisiológicas e microbiológicas. Os danos de origem mecânica devem ser considerados da maior importância para a conservação da qualidade dos frutos após sua colheita. Além de esses causarem ferimentos, amassamentos e cortes, influenciam nos outros tipos de danos - os fisiológicos e os microbiológicos.

A avaliação da qualidade do fruto deve ser acompanhada em cada fase do processo, desde sua colheita até sua comercialização. Para isso, faz-se necessária a adoção de padrões preestabelecidos, de forma a proporcionar uma classificação adequada ao produto (Chitarra \& Chitarra,1990). Dentre os frutos climatérios, a banana é um caso raro no que se refere à larga faixa de maturidade fisiológica em que pode ser colhida e induzida a amadurecer com excelente qualidade. Este fato permitiu que a maturação comercial de bananas se tornasse uma operação de rotina (Wills et al., 1982).

Dentre os parâmetros químicos mais utilizados para avaliar a qualidade pós-colheita da banana estão o pH, acidez titulável, sólidos solúveis, relação entre sólidos solúveis e acidez ou índice de maturação (IM) ou "ratio", açúcares redutores, açúcares não-

\footnotetext{
1 (Trabalho 097-06). Recebido em : 21-07-2006. Aceito para publicação em 06-07-07.

${ }^{2}$ Eng $^{\circ}$ Agr $^{\circ}$, Mestrando, CITP-FEAGRI/UNICAMP C.P.:6011, 13083-875 Campinas - SP, F: (019) 8139.9691, letícia.viviani@agr.unicamp.br.

${ }^{3}$ Eng $^{\circ}$ Agric, Prof. Assoc-MS-5, CITP-FEAGRI/UNICAMP, C.P.: 6011, 13083-875 Campinas - SP, pamleal@agr.unicamp.br.
} 
redutores, açúcares totais, substâncias pécticas e teor de amido (Chitarra \& Chitarra, 1990). Sendo a banana uma fruta climatérica, sofre profundas transformações bioquímicas após a colheita, ressaltando-se, como fenômeno metabólico de maior importância, a respiração (Rocha, 1984). Segundo Palmer (1971), durante o amadurecimento, aumenta de $20 \mathrm{mg} \mathrm{kg}^{-1} \mathrm{~h}^{-1}$ para cerca de $125 \mathrm{mg}$ $\mathrm{kg}^{-1} \mathrm{~h}^{-1}$. Nessa fase, tem-se aumento no teor de açúcares simples, aumento de ácidos simples e orgânicos (predominando o ácido málico) e diminuição dos compostos fenólicos, de menor peso molecular, acarretando redução da adstringência e aumento da acidez, além da liberação de compostos voláteis, fatores responsáveis pelo aroma e sabor, que são características fundamentais para a aceitação da fruta (Soto Ballastero, 1992). A acidez em frutos de bananeira varia de $0,17 \%$ a $0,67 \%$ (Fernandes et al., 1979); o pH, de 4,2 a 4,8 (Soto Ballastero, 1992), e o teor de sólidos solúveis aumenta até um máximo de $27 \%$, tendo pequena diminuição quando a fruta já está muito madura (Bleinroth, 1995). O conteúdo de umidade da polpa de banana verde aumenta ligeiramente, média de $70 \%$ para $75 \%$ quando completamente madura (Bleinroth, 1995).

A conversão do amido em açúcares simples é uma das mudanças mais notáveis no amadurecimento da banana. Esse é transformado, predominantemente, em açúcares redutores, glicose e frutose ( 8 a $10 \%$ ), e sacarose (10 a $20 \%$ ). Na fase madura, a porcentagem de amido é reduzida de 0,5 a 2,0 \%, dos $20 \%$, quando o fruto se apresenta verde.

As características externas de qualidade, percebidas pelo tato e pela visão, são importantes na diferenciação do produto, particularmente na decisão de compra. As características internas percebidas pelo sabor, aroma e textura ao paladar, combinadas com a aparência do produto, são importantes na determinação da aceitação pelo consumidor (Chitarra, 2000).

Os produtos frescos possuem uma atividade fisiológica que se mantém após a colheita através do consumo de suas reservas. A temperatura de armazenamento do produto é o maior determinante da taxa respiratória, observando-se redução de 2 a 4 vezes nessa taxa, a cada decréscimo de $10^{\circ} \mathrm{C}$ na temperatura. Assim, o bom gerenciamento da temperatura na pós-colheita é essencial para uma lenta deterioração fisiológica dos produtos frescos (Honório et al., 2001). A temperatura ideal de refrigeração varia para as diferentes cultivares de banana, e a exposição dos frutos a temperaturas abaixo das indicadas causa injúria pelo frio, distúrbio fisiológico que provoca o escurecimento da casca e da polpa do fruto, além da perda do sabor do mesmo (Hall, 1967; Murata, 1970; Bleinroth, 1990). A sensibilidade ao frio está estreitamente ligada à composição química da fruta, que é influenciada pelas condições climáticas e diferenças varietais (Chitarra \& Chitarra, 1990).

A refrigeração é, tecnicamente, um dos métodos conhecidos mais eficaz, que conserva o produto com características desejáveis semelhantes a seu estado inicial, retardando o processo de maturação e senescência, devido ao fato de que os mesmos experimentam processos fisiológicos e patológicos em função direta da temperatura ( Ashreae, 1994).

Segundo Chitarra \& Chitarra (1990), a ação conjunta da utilização da cadeia do frio e da embalagem adequada mantém a qualidade da banana até que ela chegue à mesa do consumidor. No acondicionamento de produtos hortícolas, a embalagem deve ser utilizada com a intenção de absorver impactos, vibrações e outros agentes externos capazes de provocar a perda de qualidade do seu conteúdo (Teruel et al., 2004). Além de proteção mecânica, as tecnologias envolvidas no desenvolvimento de embalagens para frutas e hortaliças visam também a retardar a respiração, o amadurecimento, a senescência e, conseqüentemente, todas as alterações indesejáveis advindas desses processos fisiológicos (Saratópoulos e Fernandes, 2001).

É importante ressaltar que a embalagem vem assumindo, a cada dia, uma posição de destaque na elaboração e na comercialização de um produto, quer pelo benefício da preservação das características que oferecem quando bem dimensionadas, quer pelo custo que representa no valor final do produto (Bordin, 1998). Na escolha de novos modelos, um dos pontos mais polêmicos se refere à característica de serem descartáveis ou retornáveis.

Este trabalho tem como objetivo avaliar a qualidade póscolheita da banana Prata-Anã produzida no Norte de Minas Gerais, município de Janaúba, por métodos físicos, químicos e sensoriais, relacionando os conceitos de qualidade com 3 tipos de embalagens e 2 temperaturas de armazenamento.

\section{MATERIAL E MÉTODOS}

As frutas foram adquiridas na Central de Abastecimento de Campinas - CEASA -, proveniente de produtores do Estado de Minas Gerais, município de Janaúba. A variedade utilizada foi a 'Prata-Anã'. A banana passou por todos os processos, desde a colheita até a comercialização (corte dos cachos em pencas, buquês, despistilagem, lavagem, tratamento químico, classificação e embalagem). Os frutos foram colhidos em estádio verde, grau de coloração 1 , segundo a tabela de coloração da banana proposto pelo Programa Brasileiro para a Melhoria dos Padrões Comerciais e Embalagens de Hortigranjeiros (PBMPCEH) (Brasil, 2002). Depois de acondicionados, segundo os procedimentos utilizados pelo produtor, incluindo a refrigeração e a forma de distribuição nas caixas, os frutos foram transportados até a cidade de Campinas, em caminhão-baú térmico, chegando com a temperatura da fruta entre $22^{\circ} \mathrm{C}$ e $25^{\circ} \mathrm{C}$. A seguir, foi efetuado o amadurecimento induzido, empregando-se etileno, com os frutos atingindo coloração de grau 3, segundo a tabela de coloração da banana proposto pelo PBMPCEH. O trabalho foi dividido em duas etapas de análises: frutos colhidos no verão e no inverno. Avaliou-se a qualidade físico-química e sensorial dos frutos acondicionados em três tipos de embalagens (caixa de madeira tipo torito, com capacidade para $18 \mathrm{~kg}$, com revestimento de papelão para os frutos, caixa de madeira tipo $1 / 2$ caixa, com capacidade para $13 \mathrm{~kg}$, com revestimento de papelão para os frutos, e caixa de papelão com 
capacidade para 18kg) (Figura 1) e em duas temperaturas: ambiente sem controle (testemunha); e $13^{\circ} \mathrm{C}( \pm 1)$, com controle de umidade ajustada para $90 \%( \pm 2,5)$. Embalagem A: Caixa de madeira do tipo torito modificada (com revestimento de papelão para as frutas), comumente chamada de $1 / 2$ caixa pelos produtores e distribuidores, com dimensões internas de 480 x 390 x 190 mm, e com capacidade de $13 \mathrm{~kg}$. Entre a caixa de madeira e os frutos, foi colocado revestimento de papelão com dimensões internas de 471 x 372 x $80 \mathrm{~mm}$.

Embalagem B: Caixa de madeira do tipo torito (com revestimento de papelão para as frutas): dimensões internas de 480 x 390 × $280 \mathrm{~mm}$ e com capacidade de $18 \mathrm{~kg}$. Entre a caixa de madeira e os frutos, foi colocado revestimento de papelão com dimensões internas de 471 × $372 \times 233 \mathrm{~mm}$, apresentando furos de $20 \mathrm{~mm}$, sendo 3 furos na face do comprimento e 2 furos na face da largura da embalagem.

Embalagem C: Caixa de papelão com dimensões internas de 472 x 374 × $257 \mathrm{~mm}$ e capacidade para $18 \mathrm{~kg}$ de bananas, apresentando aberturas de $40 \mathrm{~mm} \times 8 \mathrm{~mm}$ em suas laterais, sendo 3 de cada lado do comprimento e 2 em cada lado da largura. As laterais apresentavam uma abertura de $88 \times 20 \mathrm{~mm}$ para transportar a caixa.

Foram realizadas as seguintes análises físico-químicas: relação polpa/casca, através das massas obtidas, das partes referidas, em balança eletrônica digital de precisão; umidade, utilizando estufa de convecção forçada a $65^{\circ} \mathrm{C}$, por 48 horas, com os resultados em porcentagem; acidez titulável (AT) por método acidimétrico e potenciometria de acordo com metodologia descrita por Carvalho et al. (1990); $\mathrm{pH}$ por potenciometria na determinação da concentração hidrogeniônica (Laboratório de pós-colheita de frutas e hortaliças, 1988); teor de sólidos solúveis totais (SST) pelo método refratométrico, com o uso de refratômetro manual, com os resultados expressos em ${ }^{\circ}$ Brix e índice de maturação pela razão entre o teor de sólidos solúveis totais e acidez titulável do produto.

Para a avaliação dos danos físicos, foi feita a quantificação dos danos, contando-se as manchas presentes nas frutas na chegada ao centro de distribuição, no laboratório de análises e após os tratamentos citados anteriormente. Para a avaliação sensorial, empregou-se o teste de ordenação, onde os provadores foram solicitados a ordenar as amostras quanto à intensidade de característica específica do produto. A equipe foi composta por 30 provadores, onde foram solicitados a ordenar as amostras quanto à intensidade de cor (mais amarela e menos amarela) e defeitos nos frutos (maior presença de defeitos e menor presença de defeitos). Os resultados foram analisados utilizando a tabela de Newell e Mc Farlane (Meilgaard et al., 1987). Realizou-se também o teste de intenção de compra, a fim de se analisar o grau de interferência das imperfeições no fruto, onde os resultados foram representados por histograma de distribuição de notas em relação à categoria da escala.

$\mathrm{O}$ delineamento experimental utilizado foi o inteiramente casualizado (DIC), sendo a estrutura de tratamentos fatorial $(2 \times 3$ $\mathrm{x} 2$ ), frutos colhidos no inverno e no verão, 3 tipos de embalagens e 2 temperaturas de armazenamento; foram testados seis tratamentos, com cinco repetições para cada tratamento. Os resultados das características avaliadas foram submetidas à análise de variância (ANOVA), e as médias, quando significativas, comparadas pelo teste de Tukey, a 5\% e $1 \%$ de probabilidade, através do software de análise estatística STATGraphicsâ.

\section{RESULTADOS E DISCUSSÃO}

Com relação à análise sensorial para cor e imperfeições, os testes com os provadores/consumidores mostraram que não houve diferença significativa entre as amostras. O teste de intenção de compra confirmou o fato de que esse conceito pode variar de um mercado para outro, pois as amostras retiradas do armazenamento em temperatura ambiente tiveram maior índice de preferência, uma vez que apresentavam coloração próxima ao nível considerado ideal para consumo. As amostras submetidas ao armazenamento refrigerado apresentavam estádio de maturação impróprio para consumo, justificando o maior nível de incerteza em relação à compra (Figuras 2 e 3 ).

Os parâmetros físico-químicos analisados $(\mathrm{pH}$, acidez titulável, sólidos solúveis, índice de maturação, umidade e relação polpa casca), cujas médias se apresentam na Tabela 2, foram influenciados pelas diferenças entre os frutos colhidos no verão e no inverno, devido às épocas de plantio, manejo e condições fisiológicas das plantas, e diferentes temperaturas de armazenamento (ambiente sem controle e $13^{\circ} \mathrm{C}$ ) (Seymour, 1996), o que não aconteceu com o uso de diferentes embalagens, como é possível observar na Tabela 1, para as médias apresentadas. Frutos de bananeira, armazenados em câmara de refrigeração, apresentaram parâmetros físico-químicos menores do que os frutos armazenados em temperatura ambiente (Tabela 2). A temperatura de $13^{\circ} \mathrm{C}$ mostrou-se mais eficiente na conservação dos frutos (Sanches, 2002).

Quanto aos danos físicos, os defeitos leves não tiveram diferença significativa entre as embalagens; já para os defeitos graves, a embalagem de papelão apresentou $58,3 \%$ da quantidade da amostra analisada, enquanto as embalagens $1 / 2$ caixa com revestimento interno de papelão e torito com revestimento interno de papelão apresentaram 16\% cada uma delas (Figura 4). Isso ocorreu, pois algumas embalagens de papelão não suportaram o empilhamento no palete e acabaram sofrendo deformações e esmagamento das frutas (Sanches, 2002). 


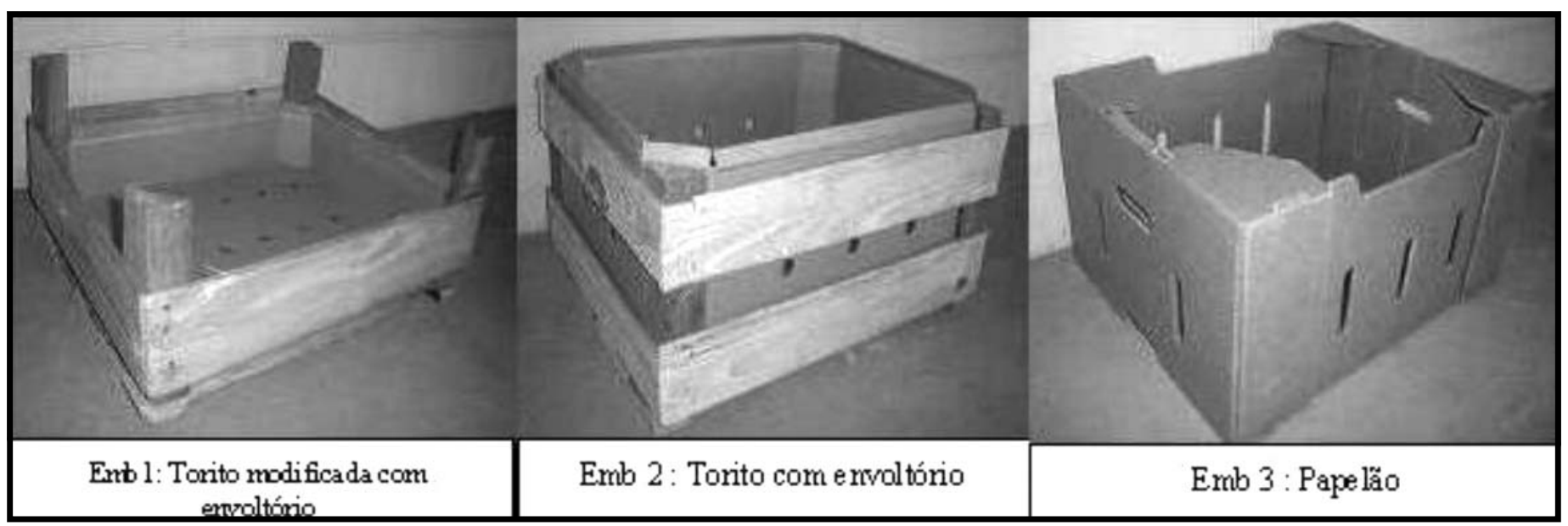

FIGURA 1 - Embalagens utilizadas para o acondicionamento das bananas.

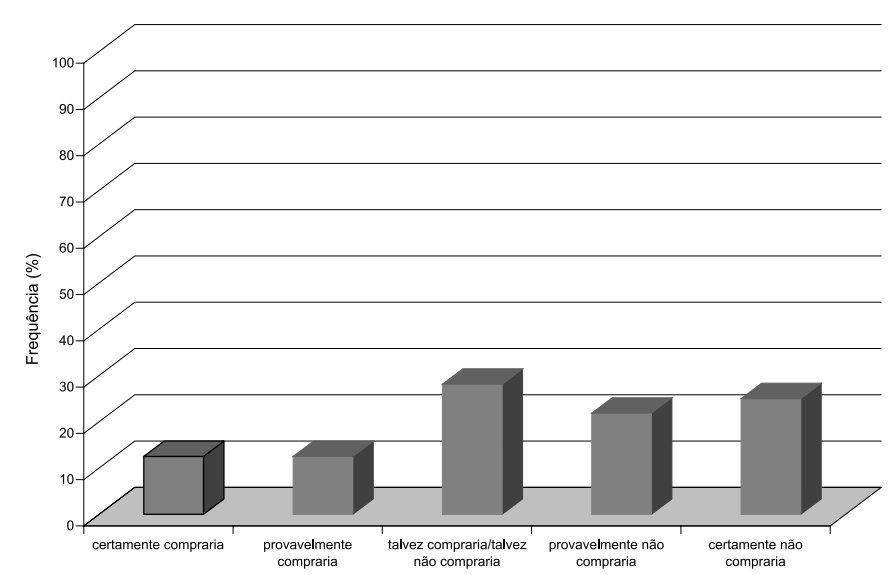

FIGURA 2 - Distribuição da intenção de compra para amostras armazenadas em temperatura ambiente.

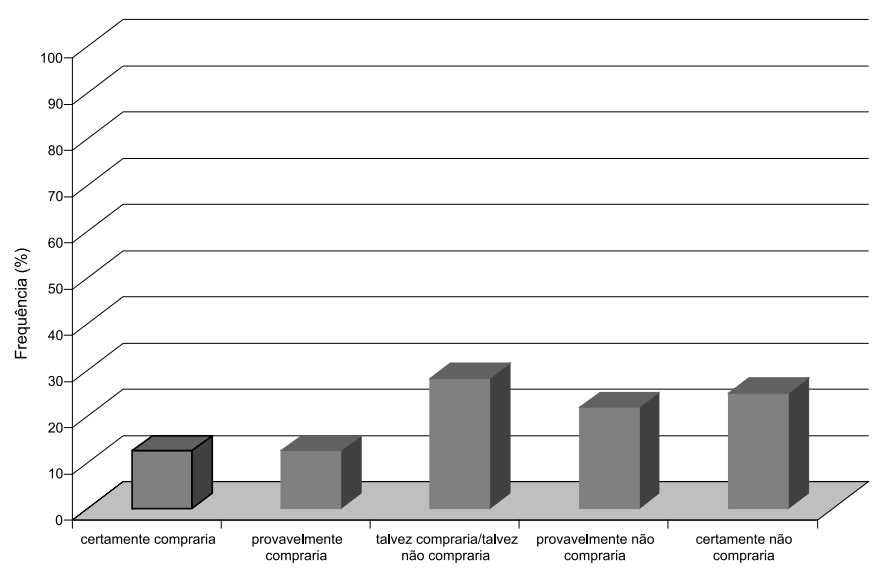

FIGURA 3 - Distribuição da intenção de compra para amostras armazenadas em temperatura refrigerada.

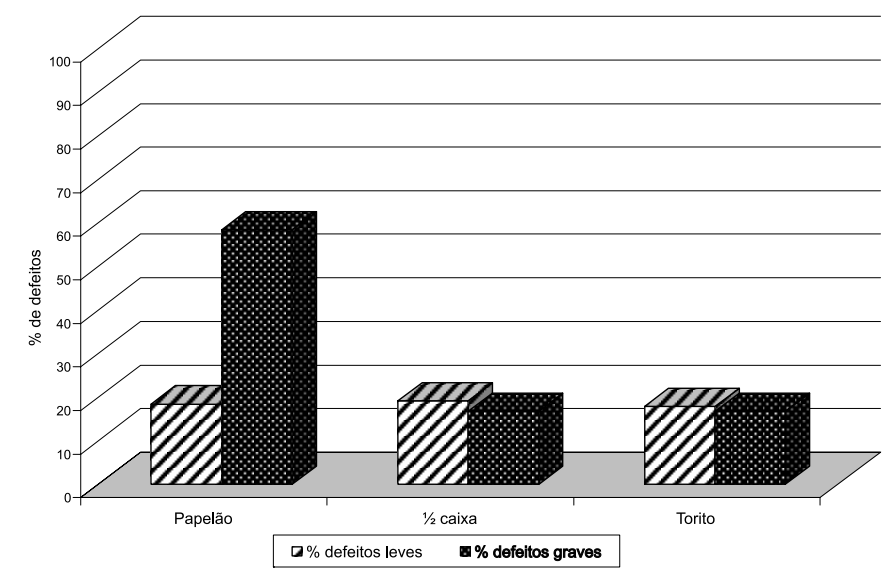

FIGURA 4 - Distribuição de defeitos leves e graves nas embalagens em estudo 
TABELA 1 - Valores médios para as características analisadas para as embalagens utilizadas nos tratamentos de verão (fase 1) e inverno (fase 2).

\begin{tabular}{|c|c|c|c|c|c|}
\hline \multirow[t]{2}{*}{$\begin{array}{c}\text { Características } \\
\text { analisadas }\end{array}$} & \multirow[b]{2}{*}{ Embalagem } & \multicolumn{2}{|c|}{ Fase 1} & \multicolumn{2}{|c|}{ Fase 2} \\
\hline & & Média & Tuckey & Médias & Tuckey \\
\hline \multirow{3}{*}{$p H$} & Papelão & 4,67 & $\mathrm{~A}$ & 4,05 & $\mathrm{~B}$ \\
\hline & Torito & 4,66 & $\mathrm{~A}$ & 4,05 & $\mathrm{~B}$ \\
\hline & $1 / 2$ Torito & 4,60 & A & 4,06 & $\mathrm{~B}$ \\
\hline \multirow{3}{*}{ Acidez total tituável } & Papelão & 0,31 & A & 0,64 & $\mathrm{~B}$ \\
\hline & Torito & 0,33 & $\mathrm{~A}$ & 0,65 & $\mathrm{~B}$ \\
\hline & $1 / 2$ Torito & 0,34 & $\mathrm{~A}$ & 0,63 & $\mathrm{~B}$ \\
\hline \multirow{3}{*}{ Sólidos sbúveis totais } & Papelão & 17,76 & $\mathrm{~A}$ & 23,01 & $\mathrm{~B}$ \\
\hline & Torito & 18,02 & $\mathrm{~A}$ & 22,56 & $\mathrm{~B}$ \\
\hline & $1 / 2$ Torito & 17,63 & $\mathrm{~A}$ & 22,23 & $\mathrm{~B}$ \\
\hline \multirow{3}{*}{ Índice de maturação } & Papelão & 56,86 & A & 36,14 & $\mathrm{~B}$ \\
\hline & Torito & 55,39 & $\mathrm{~A}$ & 35,52 & $\mathrm{~B}$ \\
\hline & $1 / 2$ Torito & 55,39 & A & 36,50 & $\mathrm{~B}$ \\
\hline \multirow{3}{*}{ Umidade } & Papelão & 67,93 & $\mathrm{~A}$ & 67,55 & $\mathrm{~B}$ \\
\hline & Torito & 67,08 & $\mathrm{~A}$ & 64,96 & $\mathrm{~B}$ \\
\hline & $1 / 2$ Torito & 67,37 & $\mathrm{~A}$ & 64,01 & $\mathrm{~B}$ \\
\hline \multirow{3}{*}{ Relação polpa/casca } & Papelão & 63,72 & $\mathrm{~A}$ & 64,56 & $\mathrm{~B}$ \\
\hline & Torito & 59,62 & $\mathrm{~A}$ & 66,38 & B \\
\hline & $1 / 2$ Torito & 63,27 & $\mathrm{~A}$ & 65,87 & $\mathrm{~B}$ \\
\hline
\end{tabular}

Médias seguidas de letras diferentes diferem pelo teste de Tuckey, a $5 \%$ de probabilidade. Para um a mesma característica analisada, médias com letras iguais, em uma mesma linha, não diferem entre si, pelo teste de Tuckey, a $5 \%$ de probabilidade.

TABELA 2 - Valores médios para as características analisadas para as temperaturas utilizadas para acondicionamento, nos tratamentos de verão (fase 1) e inverno (fase 2).

\begin{tabular}{|c|c|c|c|c|c|}
\hline \multirow[t]{2}{*}{$\begin{array}{c}\text { Características } \\
\text { analisadas }\end{array}$} & \multirow[b]{2}{*}{ Temperatura } & \multicolumn{2}{|c|}{ Fase 1} & \multicolumn{2}{|c|}{ Fase 2} \\
\hline & & Médias & Tuckey & Médias & Tuckey \\
\hline \multirow{2}{*}{$p H$} & Ambiente & 4,34 & $\mathrm{~A}$ & 4,29 & $\mathrm{~B}$ \\
\hline & Refrigerada & 4,15 & $\mathrm{~B}$ & 3,81 & $\mathrm{~A}$ \\
\hline \multirow{2}{*}{ Acidez total tituável } & Ambiente & 0,28 & A & 0,63 & B \\
\hline & Refrigerada & 0,37 & $\mathrm{~B}$ & 0,65 & $\mathrm{~A}$ \\
\hline \multirow{2}{*}{ Sólidos solúveis totai } & Ambiente & 19,67 & $\mathrm{~B}$ & 23,57 & A \\
\hline & ${ }^{\boldsymbol{s}_{\text {Refrigerada }}}$ & 15,94 & $\mathrm{~A}$ & 21,63 & $\mathrm{~B}$ \\
\hline \multirow{2}{*}{ Índice de maturação } & Ambiente & 53,26 & $\mathrm{~A}$ & 38,52 & $\mathrm{~B}$ \\
\hline & Refrigerada & 58,49 & $\mathrm{~B}$ & 33,56 & A \\
\hline \multirow{2}{*}{ Umidade } & Ambiente & 69,25 & $\mathrm{~B}$ & 66,22 & $\mathrm{~A}$ \\
\hline & Refrigerada & 65,67 & A & 65,46 & A \\
\hline \multirow{2}{*}{ Relação polpa/casca } & Ambiente & 61,53 & $\mathrm{~A}$ & 66,00 & $\mathrm{~B}$ \\
\hline & Refrigerada & 62,88 & $A$ & 65,20 & $\mathrm{~B}$ \\
\hline
\end{tabular}

Médias seguidas de letras diferentes diferem pelo teste de Tuckey, a $5 \%$ de probabilidade. Para uma mesma característica analisada, médias com letras iguais, em uma mesma linha, não diferem entre si, pelo teste de Tuckey, a $5 \%$ de probabilidade.

\section{CONCLUSÃO}

Com o presente trabalho, é possível concluir que tanto as embalagens como as temperaturas de armazenamento não interferem na intenção de compra, segundo resultados das análises sensoriais, sendo que os níveis de danos físicos e coloração foram considerados aceitáveis pelos provadores. Em relação aos atributos de qualidade física, os revestimentos proporcionam características de acondicionamento iguais para as embalagens. Sendo assim, o revestimento entre a caixa de madeira e os frutos pode ser uma alternativa de proteção sem interferência no armazenamento refrigerado.

\section{REFERÊNCIAS}

ALVES, E.J. A cultura da banana: aspectos técnicos, socioeconômicos e agroindustriais, Brasília, DF: EMBRAPA, 1999. $585 \mathrm{p}$.

ASHRAE. Methods of precooling fruits, vegetables, and cut flowers. Refrigeration Systems and Applications Handbook. C. 10. Atlanta: American Society of Heating, Refrigerating and Air Conditioning Engineers, 1994.

BLEINROTH, E. W. Banana: cultura, matéria-prima, processamento e aspectos econômicos. $2^{\mathrm{a}}$ ed. rev. e ampl. Campinas:ITAL, 1995.302p.

BORDIN, M.R. Embalagem para frutas e hortaliças: tecnologia de resfriamento de frutas e hortaliças. In: CURSO DE ATUALIZAÇÃO EM TECNOLOGIA DE RESFRIAMENTO DE FRUTAS E HORTALIÇAS, 2., 1998. Campinas: UNICAMP, 1998. p.19-27. Apostila

BRASIL. MINISTÉRIO DA AGRICULTURA E REFORMA AGRÁRIA. Proposta de regulamento técnico de identidade, embalagem e apresentação da banana. Programa Brasileiro para a Melhoria dos Padrões Comerciais e Embalagens de Hortigranjeiro. Brasília, 2002.

CARVALHO, C.R.L.; MANTOVANI, D.M.B.; CARVALHO, P.R.N.; MORAES, R.M.M. Análises químicas de alimentos. Campinas: ITAL, 1990. 121p. Manual Técnico.

CHITARRA, M. I. F. Tecnologia e qualidade pós-colheita de frutos e hortaliças. Lavras: UFLA/FAEPE, 2000. 68p.

CHITARRA, M.I.F.;CHITARRA, A.B. Pós-colheita de frutas e hortaliças. fisiologia e manuseio. Lavras..ESAL/FAEPE, 1990. 293p.

FERNANDES K.M.; CARVALHO, V.D. de; CAL VIDAL, J Physical changes during ripening silver bananas. Journal of Food Science, Chicago, v.44, n.4, p.1254-1255, 1979. 
HALL, E. G. Technology of banana marketing. Food Preservation Quarterly, Sydney,v.37, p.36, 1967.

ICEPA- INSTITUTO CATARINENSE DE PESQUISA AGROPECUÁRIA Artigos, Notícias, Previsão e estimativa das safras agrícolas no Estado de Santa Catarina. Disponível em: $<$ http://www.icepa.com.br/, 05/2002>. Acesso em: 14 mar. 2005

HONORIO, S.L.;BENEDETTI, B.; LEAL, P.A.M. Pós-colheita de produtos perecíveis. In: CONEEAGRI,18., 2001. Campinas. Anais...

LABORATÓRIO DE PÓS-COLHEITA DE FRUTAS E HORTALIÇAS. Análises laboratoriais. Lavras: UFLA/ Departamento de Ciência de Alimentos da Universidade Federal de Lavras, 1998. 55p.

MEILGAARD, M.; CIVILLE, G.V.; CARR, B.T. Sensory evaluation techniques. Florida: CRC Press, 1987.

MURATA, T. Physiological and biochemical studies of chilling injury in banana. Physiologia Plantarum, Copenhagen, v. 22, n.2,p.401-11, 1969.

OLORUNDA, A. O. Recent advances in postharvest technologies of banana and plantain in Africa. Acta Horticulturae, Wageningen,.n.540, p.517-597, 2000.

PALMER, J. K. The banana. In: HULME, A. C. The biochemistry of fruits and their products. London: Academic Press, 1971. v.2, p.65-105.

ROCHA, J. L. V. Fisiologia pós-colheita de banana. In: SIMPÓSIO BRASILEIRO SOBRE BANANICULTURA, 1., 1984, Jaboticabal. Anais... Jaboticabal: FCAV, 1984. p.353-67.
SANCHES, J. Qualidade pós-colheita de bananas (Musa cavendishii) 'nanicão', através da classificação de defeitos físicos, embalagens e tecnologia do frio. 2002. 82f. Dissertação (Mestrado em Tecnologia Pós-Colheita) - Faculdade de Engenharia Agrícola, UNICAMP, Campinas. 2002.

SARANTOPOULOS, C. I. G. L.;FERNANDES, T. Embalagens ativas. Campinas: ITAL, 2001. CETEA Informativo. Disponível em $<$ http://www.jorplast.com.br/jpout01/pag11.html >. Acesso em: 20 dez. 2002

SEYMOUR G. B. Banana. In Seymour G. B., Taylor J. E., Tucker G. A. (Ed.). Biochemistry of fruit ripening. $2^{\text {nd }}$ ed. London: Chapman \& Hall, 1996.

SOTO-BALLESTERO, M. Bananos: cultivo y comercialización. $2^{\text {nd }}$ ed. San José: Litografia e Imprenta LIL, 1992. 674p.

STATGraphicsâ Plus for windows 4.1 by statistical graphics corp. professional version.

TERUEL, B.; CORTEZ, L.; LEAL, P.; NEVES FILHO, L. Forced-air cooling of banana. Revista Brasileira Fruticultura, Jaboticabal, v.24, n.1, p.142-146, 2004 [on line]. Disponível em: <http:// www.scielo.br/scielo.php?script $=$ sci_arttext\&pid $=\mathrm{S} 0100$ 29452002000100031\&lng=en\&nrm=iso >. Acesso em: $20 \mathrm{dez} .2002$

WILLS, R. B. H. et al. Postharvest: an introduction to the physiology and handling of fruit and vegetables. $2^{\text {nd }}$ ed. rev. Kensington: New South Wales University Press, 1982. 